\title{
Persons and Pronouns: Exploring Clitics in Judeo-Spanish
}

\author{
Naomi Kurtz \\ University of Chicago \\ nkurtz@uchicago.edu
}

Received: $15-03-2021$

Accepted: $30-09-2021$

Published: 22-02-2022

How to cite: Kurtz, Naomi. 2022. Persons and pronouns: Exploring clitics in JudeoSpanish. RLLT17, eds. Ora Matushansky, Laurent Roussarie, Michela Russo, Elena Soare \& Sophie Wauquier. Special issue of Isogloss Open Journal of Romance Linguistics $8(2) / 7,1-22$.

DOI: https://doi.org/10.5565/rev/isogloss. 138

\begin{abstract}
Optional versus obligatory clitic doubling and the person-case constraint (PCC) repair constitute two puzzles researchers haven't fully addressed. In Judeo-Spanish, doubling is obligatory for third person accusative strong pronouns; for all other arguments, doubling is optional. This analysis contends objects are generated with corresponding clitics in the syntax. The realization of clitics is regulated by functional heads: $v^{0}$ and $\mathrm{X}^{0}$, a head located beneath $v^{0} . \mathrm{X}^{0}$ is hypothesized to be a probe specified only for person; critically, third person accusative strong pronouns lack person features (Anagnostopoulou 2003), while other arguments bear person features. Optional doubling is regulated by alternations in Agree with $v^{0}$ or $\mathrm{X}^{0}$. An argument that appears without a co-referring clitic is derived via agreement with $\mathrm{X}^{0}$. This interaction triggers deletion of clitics' phi-features, which causes them to be null. Overt cliticization is derived via agreement with $v^{0}$. Obligatory doubling is derived via Agree strictly with $v^{0}$; third person accusative strong pronouns
\end{abstract}


cannot be potential goals for $\mathrm{X}^{0}$ since they lack person features. Apart from doubling, $\mathrm{X}^{0}$ generates the PCC repair by blocking Agree between $v^{0}$ and dative clitics, causing dative arguments to appear without a matching clitic, and by eliminating intervention effects between $v^{0}$ and accusative clitics.

Keywords: clitic doubling, person-case constraint, agreement, syntax

\section{Introduction}

Clitic doubling, the person-case constraint (hereafter PCC), and the person-case constraint repair have generated extensive debate within the syntactic literature. I aim to shed new light on these puzzles by advancing a unified account of both doubling and the personcase constraint repair. In particular, the analysis here investigates these clitic behaviors in Judeo-Spanish (hereafter JS). In JS, clitic doubling is obligatory only for third person accusative strong pronouns: for all other arguments, doubling is optional. The proposal advanced in this paper argues that all objects co-occur with a corresponding clitic in the syntax; overt pronunciation of a clitic depends on which functional head said clitic has agreed with. This same derivational machinery of agreement with functional heads is extended to the PCC repair: a dative argument will be realized without a matching clitic if that clitic is licensed by a particular functional head. This analysis maintains that constructions without doubling - that is, solely cliticization-are derived via pro-drop of arguments; pro-drop is construed as head ellipsis, as in Saab (2009a, 2009b, 2016).

Importantly, this analysis differs from previous work in several distinct and novel ways. Firstly, unlike Cuervo (2003), it does not attribute the optionality or obligatoriness of doubling to different underlying argument structures, nor does it attribute optional versus obligatory doubling to the syntactic category of clitics themselves (agreement markers versus determiner cliticizations), as in Ormazabal and Romero (2013). Optional doubling has been extensively observed in the literature, but, to my knowledge, there is no proposal yet that aims to explain why doubling should or should not be mandatory-a question distinctive from whether doubling corresponds to different argument structures, as in Cuervo (2003). It is also crucial to note that this analysis examines only person-based asymmetries pertaining to doubling; it does not explore other factors that restrict doubling, such as specificity, animacy, or definiteness.

Secondly, in contrast to other studies of PCC repairs, this analysis does not ascribe the realization of this construction to animacy-related $\phi$-features (e.g., Bonet 2008). Moreover, it does not construe the repair as an actual syntactic repair, as in Rezac (2011). Instead, rather, the PCC repair is viewed as an alternate structure; the same underlying syntax is responsible for the PCC and its repair. Such a proposal has precedent in Ormazabal and Romero (1998), who also argue that in ditransitive constructions dative arguments, both clitics and prepositional phrases, share the same syntax. Further, although perhaps some ideas offered in this paper are implicit or nascent in the proposals above-and in others, potentially - this analysis makes explicit the connection between clitic doubling, the PCC, and the PCC repair. 
The data that comprise the empirical foundation for this analysis primarily come from original field work with a native JS speaker. Research was conducted over a period of several months. The consultant was a native speaker of JS. Given the small and still diminishing number of native (or fluent) JS speakers, I was only able to locate one consultant whose command over the language allowed me to investigate clitics in depth. Data were collected via elicitation tasks (grammaticality judgments), interviews, and oral histories from the consultant's life. Given that the consultant spoke JS infrequently in daily life, and given the scarcity of cohesive JS-speaking communities and native speakers in existence today, the speaker's judgments were occasionally supplemented with data taken from written publications and digital materials.

Concerning theoretical research on JS, to date little has been done on the language's syntax. This analysis thus seeks to highlight the place of JS, a language that has not received the rigorous scientific attention it warrants. From a more macroscopic perspective, this study aims to contribute to the theoretical landscape of pronouns by mining an understudied and critically endangered language. This paper is organized as follows: Section 2 reviews previous studies of clitic doubling and provides an analysis of doubling in JS; Section 3 examines the PCC and PCC repair construction; and conclusions are in Section 4.

\section{Clitic Doubling}

Although clitic doubling in Spanish has been well studied, there has been very little research on doubling in JS. Before introducing the relevant doubling patterns, it is first necessary to outline the pronominal system in JS.

Like Spanish (Ordóñez 2012), JS possess two types of pronoun: strong pronouns, or "pronombres tónicos," and clitics, or "pronombres átonos." Strong pronouns are full phrases. Clitics are deficient in that they are morphological heads that attach phonologically to other morphological units. More precisely, clitics are heads that attach to larger heads, which together form a prosodic unit (Ordóñez 2012). As in Spanish, JS has only object clitics, i.e., clitics are never subjects. Strong pronouns and clitics are dissimilar in other ways, syntactically and morphologically. ${ }^{1}$ Since these properties have no direct bearing on the puzzles at hand, the reader is referred to Halpern (1998) and Fernández Soriano (1993) for other distinguishing characteristics of clitics and strong pronouns. For more articulated typologies of pronouns, see Cardinaletti and Starke (1994) and Déchaine and Wiltschko (2002).

\subsection{JS Clitic Doubling}

Clitic doubling can be defined as a construction in which a matching clitic co-occurs with a DP in argument position (Anagnostopoulou 2017: 2). Clitic doubling has been found in many languages including Romance, Semitic, Albanian, Greek, and Slavic (e.g., Strozer 1976, Rivas 1977, Aoun 1981, 1999, Jaeggli 1982, 1986, Drachman 1983, Borer 1984, Philippaki-Warburton 1987, Fykias 1988, Suñer 1988, Torrego 1988, DobrovieSorin 1990, 1994, Massey 1992, Sportiche 1993, 1996, 1998, Anagnostopoulou 1994,

$1 \quad$ For example, clitics cannot be coordinated, modified, or focalized, nor can they appear in isolation; strong pronouns can easily be coordinated, modified, focalized, or emphasized, and they can appear in isolation (Ordóñez 2012). 
1999, 2003, Uriagereka 1995, Bleam 1999, Kalluli 1999, Petkova Schick 2000, Tsakali 2006).

Clitic doubling in JS parallels that in modern Spanish in several respects. Doubling of dative lexical DPs is optional; and as in Rioplatense and Andean dialects of Spanish (Ordóñez 2012), accusative lexical DPs can be optionally doubled with a corresponding clitic. Note that Standard Spanish disallows doubling of accusative lexical DPs (Bleam 1999). However, JS displays an optionality with doubling not found in any dialect of Spanish. In Spanish, all strong pronouns are obligatorily doubled (Ordóñez 2012). In JS, only third person accusative strong pronouns are obligatorily doubled. For all other arguments, clitic doubling is optional. Contrast (1-2) with (3-5). The former illustrate doubling of a third person accusative strong pronoun, and the latter, of a first person accusative strong pronoun. ${ }^{2}$

(1) $\mathrm{Lo}_{i}$ vido a él ${ }_{i}$.

3SG.M.ACC saw.3SG.PRET DOM him

"S/he saw him."

(2) *Vido a él. saw.3SG.PRET DOM him

"S/he saw him."

(3) (Mos) vido a mozotros.

1PL.ACC saw.3SG.PRET DOM us

"S/he saw us."

(4) Los mansevos eskucharon a mosotros... the young.people heard.3PL.PRET DOM us

"The young people heard us..."3

(5) ma si mozotros matamos a ti seras menospresyado en but if we kill.1PL.PRES DOM you.SG will.2SG.FUT scorned.PST.PART by boka del mundo...

mouth of.the world

"but if we kill you, you will be scorned by the mouth of the world..."4

As in (1) and (2), a third person accusative strong pronoun cannot appear without a co-referring clitic. However, a first person plural clitic can be omitted, and the strong

2 I have found a handful of anomalous examples in written corpora in which a third person accusative pronoun is un-doubled. Since these examples date back to several centuries ago, it is not possible to confirm whether these anomalies reflect an idiosyncratic usage or a genuine pattern, distinct from that of the modern JS of the consultant.

3 (4) is taken from a post about the second International Ladino Day, which was held at Tufts University in 2014. The full excerpt is accessible at https://esefarad.com/?p=61020. Note, too, that in JS, the spelling of the first person plural pronoun varies: it can be spelled both as "mozotros" and "mosotros."

4 (5) comes from a text entitled "Pan de Oro" from Me'Am Lo'ez, a commentary on the Tanakh (Hebrew Bible) and one of the first major printings of Ladino in the Ottoman Empire, which dates back to the eighteenth century. The text is accessible at https://esefarad.com/?p=72599. 
pronoun may be un-doubled (3-4). A second person singular strong pronoun can likewise be un-doubled (5). Note that first person singular and second person plural accusative strong pronouns are also optionally doubled. Further, observe that JS, like Spanish, has "personal $a$," labelled here as "DOM" for "Differential Object Marker." In addition to accusative strong pronouns, other kinds of objects are optionally clitic doubled. To begin, dative strong pronouns do not require a co-referring clitic. ${ }^{5}$

(6) (Mo) lo mandó a mozotros.

1PL.DAT 3SG.M.ACC sent.3SG.PRET to us

"S/he sent it to us."

(7) (Mos) mandó el livro a mozotros.

1PL.DAT sent.3SG.PRET the book to us

"S/he sent the book to us."

(8) Disho a el: Siendo me konvidates...

told.3SG.PRET to him being.PRS.PART 1SG.ACC invited.2PL.PRET

"He said to him: Since you have invited me..."6

Dative strong pronouns, like the first person plural "mozotros," can appear with or without the corresponding first person plural clitic, "mos." Further, the dative clitic is optional regardless of whether the direct object is another clitic (6) or a lexical DP (7). This pattern of optional clitic doubling holds for dative strong pronouns in all persons (first, second, and third) and both numbers (singular and plural). Observe that in (8), a dative third person pronoun appears un-doubled. Lastly, if a strong pronoun object is not overt, the clitic must be pronounced:

(9) *Vido.

saw.3SG.PRET

Intended: "S/he saw him/you/me."
(10) Mos vido.

1PL.ACC Saw.3SG.PRET

"S/he saw us."

Apart from strong pronouns, doubling is also possible with lexical DPs. JS dative lexical DPs can optionally occur with a matching clitic - the same pattern holds for modern Spanish (Ordóñez 2012).

(11) Rachel $\left(\mathrm{le}_{i}\right)$ mandó el livro a la ijika ${ }_{i}$. Rachel 3SG.DAT sent.3SG.PRET the book to the girl

"Rachel sent the book to the girl."

As shown in (11), the dative clitic can be included or omitted; either sentence variant is well formed. Beyond datives, accusative lexical DPs may be optionally doubled-a construction also found in Rioplatense and Andean dialects (Ordóñez 2012). Standard Spanish disallows accusative lexical DP doubling (Bleam 1999).

$5 \quad$ The first person plural clitic "mos" reduces to "mo" before a third person clitic.

6 (8) comes from Avram ben Moshe Finci's translation of the Zohar. The text is accessible here: https://www.proquest.com/docview/2536461934. 
$\left(\mathrm{La}_{i}\right)$ vido a Rachel $_{i}$.

3SG.F.ACC saw.3SG.PRET DOM Rachel

"S/he saw Rachel."

As with dative DPs, corresponding clitics are not required for accusative lexical DPs (12). Thus, the accusative DP "Rachel" need not co-occur with the accusative feminine clitic. In summation of the data in (1) through (12), the following generalization emerges: clitic doubling is mandatory only for third person accusative strong pronouns and what are here termed "covert arguments," i.e., arguments that are construed to be syntactically present but null (as in (9)). The next section discusses previous accounts of clitic doubling, upon which this analysis builds.

\subsection{Analyzing JS Doubling}

With respect to doubling, one predominant theory is the so-called "big DP hypothesis" (Torrego 1988, Uriagereka 1995, Anagnostopoulou 1999, 2003, 2004, Belletti 1999, 2005, Bleam 1999, Cecchetto 2000, Roberts 2010, Nevins 2011, Arregi \& Nevins 2012). According to this theory, clitics and their associates form a constituent: the two are basegenerated within the same DP, from which the clitic extracts at some point in the derivation. There are a variety of formulations of the "big DP," but the one most similar to that in this analysis is Papangeli's (2000). For Papangeli, the clitic and its associate are generated in one functional projection. The big DP in (14) is the structure Papangeli postulates for doubling in Modern Greek, as illustrated in (13) (2000: 473-474).

$$
\begin{aligned}
& \text { ton idha to Jani. } \\
& \text { 3SG.M.ACC saw.1SG the Jani.ACC } \\
& \text { "I saw Jani." }
\end{aligned}
$$

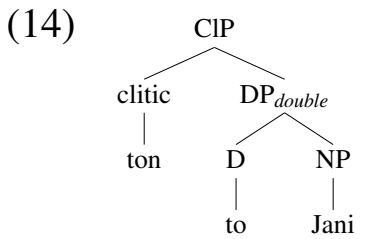

In (14), the clitic is the head of a ClP, which takes the DP it doubles as its complement. The clitic will raise out of CIP to incorporate with the verb. As for cliticization, this analysis follows Rezac (2008), Roberts (2010), and Preminger (2019) and assumes it is long head movement. The cliticization process is in (15), which comes from Preminger (2019). This structure is adapted from Preminger's (34). Example (15) depicts the big DP hypothesized in this analysis, which is formally introduced below; in Preminger, the clitic is a $\mathrm{D}^{0}$ that takes an NP complement.

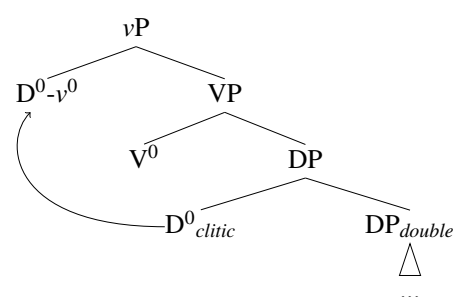

In (15), the clitic, $\mathrm{D}^{0}$, moves to $v^{0}$ (or potentially to a head higher than $v^{0}$ ), skipping over $\mathrm{V}^{0}$ and violating the Head Movement Constraint (HMC) (Travis 1984). ${ }^{7}$ With the

$7 \quad$ As to why head movement is non-local, Preminger (2019) cites data from the ordering of lexical verbs and auxiliaries in French, which suggests that the clitic moves over $\mathrm{V}^{0}$. 
relevant theoretical background now having been established, the next section presents the account of clitic doubling proposed here.

This analysis adopts a variant of the big DP hypothesis: arguments, both strong pronouns and lexical DPs, are first merged in a DP also containing their corresponding clitics. Thus, all arguments are doubled in their syntax. This version of the big DP is comparable to Papangeli's in that the clitic takes the argument as its complement. ${ }^{8}$ Firstly, recall that only third person accusative strong pronouns have a mandatory clitic. In contrast, a matching clitic is optional for all other objects. This analysis attributes the doubling asymmetry to the lack of person features in third person accusative strong pronouns. Crucially, other arguments do have syntactically active person features. The structure in (16) exemplifies the big DP structure for third person accusative strong pronouns. Accusative lexical DPs $d o$ have person features (among other phi-features) that are shared with clitics (17).

(16)

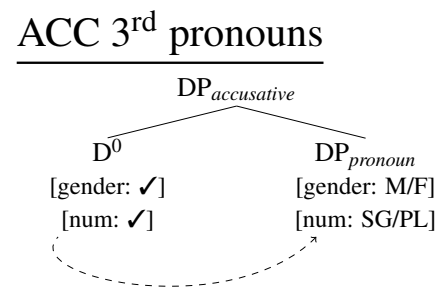

(17)

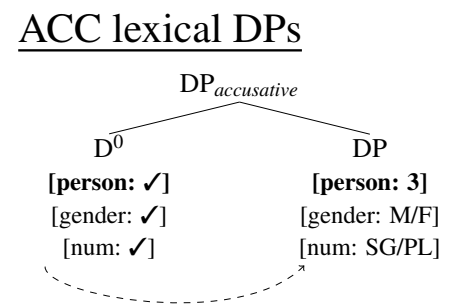

Clitics are hypothesized to have unvalued phi-features, which are valued by the features of the argument, perhaps via Agree or Merge. As in (16), third person accusative pronouns lack person features. Therefore, only gender and number are shared between associate and clitic. In that regard, this analysis borrows from Anagnostopoulou (2003), who contends that third person accusative pronouns have no person features, while third person dative pronouns do. Conversely, the phi-features of accusative lexical DPs, including person, are acquired by the clitic (17). Somewhat similarly to Anagnostopoulou (2003), Ormazabal and Romero (2013) argue that third person accusative strong pronouns are unique. According to Ormazabal and Romero, third person accusative clitics are incorporated determiners, while all other clitics are agreement markers. This analysis is reminiscent of these accounts in some respect. However, it departs from both Anagnostopoulou and Ormazabal and Romero in a critical way: here, the unique element is not the third person accusative clitic, but the strong pronoun associate. A more precise articulation of this distinction is: because the third person accusative strong pronoun lacks person features, the accompanying clitic will be unable to inherit any person features from that strong pronoun and ultimately also lack such features itself. Conversely, if a clitic doubles any dative argument (strong pronoun or lexical DP) or an accusative first or second person accusative pronoun, it will acquire multiple phi-features from its associate, respective to the argument that it doubles. Importantly, these clitics will inherit person features, among other features.

8 This big DP departs from that of Uriagereka (1988, 1995, 1996). For Uriagereka, for doubled third person accusative clitics, the double is generated in the specifier of $\mathrm{D}^{0}$ (the clitic); for first and second person clitics, the double is an adjunct. 
(18)

DAT lexical DPs \& pronouns

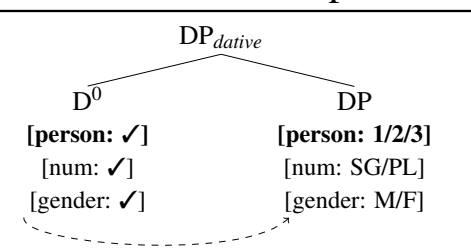

(19)

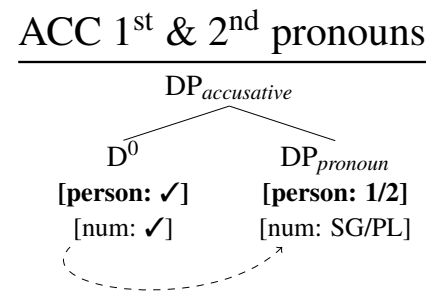

The tree in (18) depicts the big DP structure for all datives, lexical DPs and strong pronouns. That in (19) depicts the big DP for first and second person accusative strong pronouns, which bear person features.

Apart from the difference in featural composition between third person accusative pronouns and all other arguments, another key component of deriving optional versus obligatory doubling consists of two functional heads located above big DPs: $v^{0}$ and an optional functional head, $\mathrm{X}^{0}$. The posited structure for these functional heads and a big DP is:

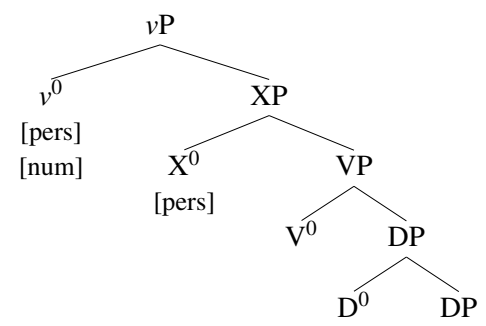

Positioned above the big DP but below $v \mathrm{P}$ is $\mathrm{X}^{0}$, a probe specified solely for an unvalued person feature. In contrast, $v^{0}$ is a probe specified for several features. In other words, $v^{0}$ is not just a person probe: it has unvalued person, number, and perhaps gender features. $\mathrm{X}^{0}$ is the determining factor in deriving constructions with either obligatory or optional doubling. To be precise, $\mathrm{X}^{0}$ regulates whether arguments can surface with or without a co-referring clitic. The properties of $\mathrm{X}^{0}$ are, at this point, somewhat stipulative: e.g., $\mathrm{X}^{0}$ 's optional presence or absence in a structure or any additional defining characteristics of the head. Further, I remain agnostic about the nature of $\mathrm{X}^{0}$ : e.g., whether its presence or absence correlates with semantic or structural differences. But an avenue of fruitful inquiry might be more precisely defining this functional head.

Constructions in which arguments appear without a matching clitic do, in fact, involve a clitic. However, in these environments, the clitic is covert. Such constructions are derived by means of Agree between clitics and the $\mathrm{X}^{0}$ head. If $\mathrm{X}^{0}$ is present in the structure, it values its person feature on a clitic specified for person via Agree. This interaction blocks Agree between a clitic and $v^{0}$. Importantly, I hypothesize that overt cliticization is always generated via Agree with $v^{0}$. The derivation in (21) is for a first person accusative strong pronoun, but the same derivation applies to second person accusative pronouns, all dative pronouns, and all lexical DPs. Sample derivations for optional doubling are below. 
(21)

$\underline{\text { UN-DOUBLING: vido a mí }}$

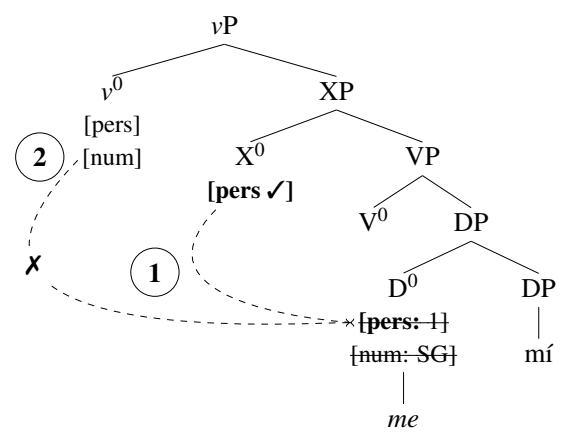

In Step $1, \mathrm{X}^{0}$ probes to value its person feature [pers] and finds $\mathrm{D}^{0}$, the clitic. $\mathrm{X}^{0}$ consequently values its [pers] feature on $\mathrm{D}^{0}$. Agreement with $\mathrm{X}^{0}$ causes the clitic to be null. Specifically, beyond valuing its own person feature, $\mathrm{X}^{0}$ causes deletion of clitics' phi-features: without phi-features, clitics are consequently covert. In other words, in superficially un-doubled structures, clitics are null but still syntactically generated. Deletion of phi-features is addressed in Section 2.3. Further, in Step (2) in (21), agreement between $\mathrm{X}^{0}$ and a clitic blocks agreement with $v^{0}$ : the clitic can no longer be a viable goal for $v^{0}$ after the prior application of Agree with $\mathrm{X}^{0}$. If $v^{0}$ cannot agree with the clitic, there will be no overt cliticization. However, if $\mathrm{X}^{0}$ is absent from the structure, the probe on $v^{0}$ will agree with the clitic for its unvalued phi-features. This analysis stipulates that $v^{0}$ s unvalued phi-features are person and number, but $v^{0}$ could also have an unvalued gender feature. Nothing in the analysis hinges on $v^{0}$ 's specific features, except that $v^{0}$ is not strictly a person probe.

\section{DOUBLING: me vido a mí}

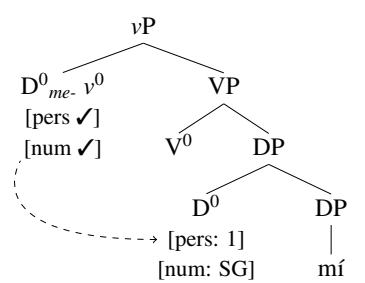

Agree between $v^{0}$ and the clitic causes the clitic to adjoin to $v^{0}$. Further, if $v^{0}$ agrees with the clitic, and not $\mathrm{X}^{0}$, no deletion of the clitic's phi-features occurs. The argument may be overt or covert (see Section 2.3). Recall that the derivations in (21) and (22) are for all arguments that permit optional doubling: all dative arguments, accusative first and second person pronouns, and lexical DPs. But if the argument is a third person accusative strong pronoun, for which doubling is mandatory, the corresponding clitic never interacts with $\mathrm{X}^{0}$, as both the argument and its corresponding clitic have no person features: 


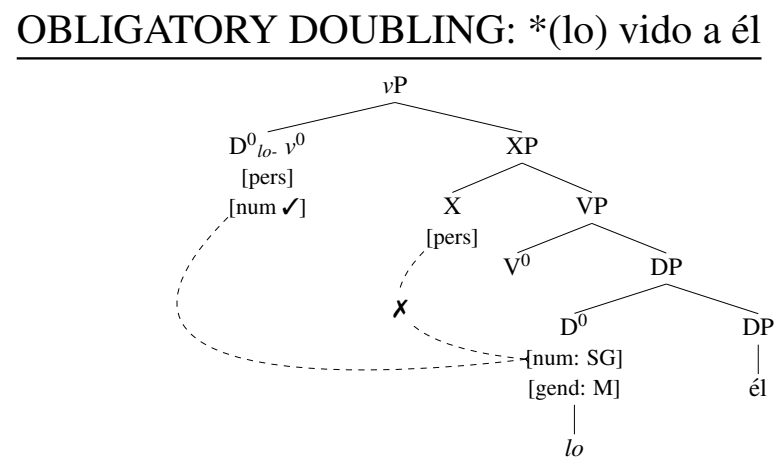

The presence of $\mathrm{X}^{0}$ has no effect on doubling for third person accusative pronouns. If $\mathrm{X}^{0}$ is present, it cannot agree with the clitic because the clitic lacks a person feature, and $\mathrm{X}^{0}$ is a person probe. $v^{0}$ will then agree with the clitic for other phi-features (number and perhaps gender), and the clitic will adjoin to $v^{0}$, a process triggered by Agree. If $\mathrm{X}^{0}$ is absent, the same derivation holds: $v^{0}$ will agree with the clitic and yield cliticization. Overt or covert realization of the argument is possible, as for other arguments whose corresponding clitics agree with $v^{0}$.

By way of concluding this section, recall from Section 2.1 that the critical difference between JS and modern Spanish is that in the former, doubling is obligatory only for third person accusative strong pronouns, but in the latter, doubling is obligatory for all strong pronouns. I would like to tentatively suggest that Spanish lacks the hypothesized $\mathrm{X}^{0}$ head; overt cliticization is invariable, since the only available probe is $v^{0}$, and strong pronouns must therefore always appear doubled. A total absence of $\mathrm{X}^{0}$, however, seems to predict that all arguments, strong pronouns and lexical DPs alike, will be obligatorily doubled in Spanish - a prediction not borne out. But perhaps other factors, well beyond the scope of this analysis, regulate the overtness of clitics that co-occur with lexical DPs. A more explicit, in-depth comparison between JS and Spanish could be informative, as it may reveal new insights on doubling and confirm or disprove this analysis. Such questions I leave for future research.

\section{3. pro-Drop}

Another aspect of clitic doubling that must be explained is bare cliticization, i.e., clitics that do not double overt arguments. This analysis views covert arguments as an instance of pro-drop. Recall that JS prohibits pro-dropped objects. Thus the example in (24), repeated from (9), is ungrammatical.

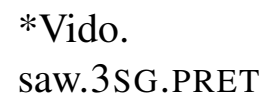

*Vido. saw.3SG.PRET

Intended: "S/he saw him/you/me."

Example (24) reveals that at least one element must be overt. To reiterate the claims outlined above: clitics will be un-pronounced as a result of phi-feature deletion via agreement with $\mathrm{X}^{0}$. Furthermore, if the clitic is un-pronounced, the argument must be overt. Conversely, clitics will be overt if they have agreed with $v^{0}$ and retain their phi-features. In this case, the argument may or may not be overt. Or, to phrase the problem alternatively: covert arguments are obligatorily clitic doubled. As a solution to this puzzle, Saab (2009a, 
2009b, 2016)'s analysis of pro-drop is adopted. For Saab, pro-drop is head (or morphological) ellipsis at PF. Ellipsis is licensed if there is a formally identical antecedent. His definition of head ellipsis is in (25), which Saab terms "I-assignment" (2016), Saab's (10):

(25) Morphological I-Assignment (Head Ellipsis)

Given a morphosyntactic word (MWd), assign a [+I] feature to $\mathrm{Y}^{0}$ if and only if there is a node $\mathrm{X}^{0}$ identical to $\mathrm{Y}^{0}$ contained in a MWd adjacent or immediately local to $\mathrm{Y}^{0}$ (where the notion of contained is reflexive).

Insertion of the $[+\mathrm{I}]$ feature at $\mathrm{PF}$ blocks lexical insertion rules that otherwise would apply to terminal nodes. Saab implements head ellipsis for pro-drop of subjects in Spanish: subjects will be elided (i.e., marked with the $[+\mathrm{I}]$ feature) when there is an identical agreement morpheme (AGR) on the verb. Saab's proposal can be extended to pro-dropped arguments in doubling constructions. More specifically, an un-doubling construction (one with only bare cliticization) will be generated via head ellipsis of the argument. Given that clitics and arguments must match in phi-features, clitics act as potential antecedents. Ellipsis will be licensed if the clitic and argument are identical in their features.

pro-drop: me vido

(a)

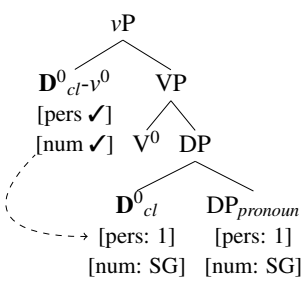

(b)

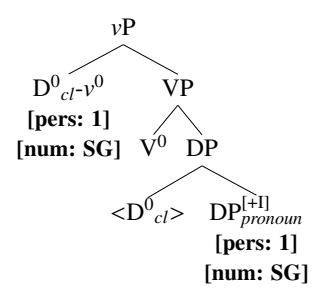

Examples (26a-b) depict how pro-drop occurs for first person singular pronouns, but these derivations apply to all null arguments. In (26a), $v^{0}$ agrees with the clitic and triggers cliticization in the narrow syntax. ${ }^{9}$ Then as in (26b), at PF, after linearization (Embick 2007, Saab 2016), the resulting configuration meets the criteria for head ellipsis: $\mathrm{D}^{0}-v^{0}$, the complex head composed of the clitic and $v^{0}$, is a morphological word adjacent to the argument, and the clitic is formally identical to the argument, since it retains its phifeatures. Therefore, the $[+\mathrm{I}]$ feature is inserted on the argument, as in $(26 \mathrm{~b})$, and lexical insertion rules are blocked from applying on this node. However, if instead $\mathrm{X}^{0}$ agrees with the clitic, the clitic's phi-features will be deleted, and this interaction prevents the clitic from serving as an antecedent for the argument. Thus, ellipsis cannot be licensed.

(27) NO pro-drop: vido *(a mí)

(a)

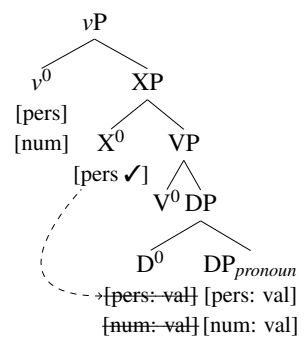

(b)

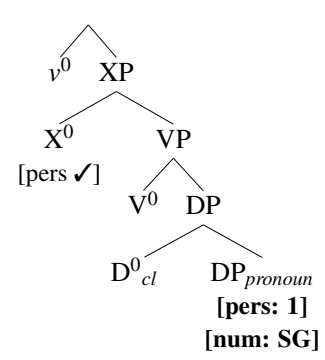

$9 \quad$ Not shown is head movement that yields the complex head of clitic, $v^{0}$, and $\mathrm{V}^{0}$, the lexical verb. 
The narrow syntax is in (27a), in which $\mathrm{X}^{0}$ agrees with the clitic for person. The result of Agree is that the clitic's phi-features are deleted. The issue of how deletion occurs is addressed shortly. Further, as depicted in (27b), at PF, the conditions for head ellipsis are not satisfied because the clitic and argument are no longer formally identical (i.e., the clitic has no has phi-features). Consequently, the $[+\mathrm{I}]$ feature will not be inserted on the argument, $\mathrm{DP}_{\text {pronoun }}$, and lexical insertion rules apply: the argument will be overt.

Pro-drop of an argument is unavailable if a clitic's phi-features are deleted through agreement with $\mathrm{X}^{0}$. Three potential means of feature deletion are considered, two of which occur at PF, and the third, in the syntax. The first is total impoverishment at PF (Bonet 1991, Noyer 1992, 1997, Halle \& Marantz 1993). Baier (2016, 2018) argues for an analysis of total impoverishment for anti-agreement phenomena. In particular, he points out that anti-agreement manifests when total (or partial) impoverishment applies to a feature bundle containing phi-features and a $w h$-feature, $[\phi, \mathrm{WH}]$, in the morphological component. The relevant aspects of Baier's analyses are explored as follows. Example (28) is adapted from Baier's (1) and (2) (2016).

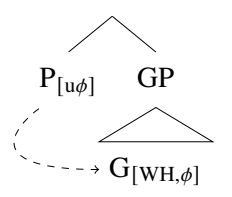

Feature Bundle on P After Agree: $[\phi, \mathrm{WH}]$

$\mathrm{P}$ is a phi-probe that can agree with a goal, G, specified for $\phi$ - and $w h$-features. $\mathrm{G}$ corresponds to the argument that is $\overline{\mathrm{A}}$-extracted; P corresponds to the $\mathrm{Agr}^{0}$ head marked for wh-agreement and anti-agreement (disrupted phi-agreement, in Baier's verbiage). Following Deal (2015), Baier maintains that a probe may copy supersets of the feature it searches for. Therefore, P, a phi-probe, may copy $[\phi]$ and $[\mathrm{WH}]$ from $\mathrm{G}$. This process creates the feature bundle on $\mathrm{P}$ in (28). However, if a language's affixes that index $\overline{\mathrm{A}}$ extraction are incompatible with that feature bundle, an impoverishment rule deletes certain features on P. Baier posits the impoverishment rule in (29), his (3) (2016).

(29) Impoverishment Deletes $[\phi]$

$$
[\phi] \rightarrow /[\ldots, \mathrm{WH}]
$$

This rule deletes all phi-features in the presence of a $[\mathrm{WH}]$ feature. Consequently, no more specific agreement exponent may be inserted into the $\mathrm{Agr}^{0}$ node, and anti-agreement (i.e., disrupted agreement) surfaces, in place of full phi-agreement. Baier's analysis can be transferred to deletion of phi-features in clitics. The one necessary change is that deletion is due to an impoverishment rule that acts on phi-features in the presence of a feature inherited by a clitic from $\mathrm{X}^{0}$. For simplicity, this feature is called [x].

(30)

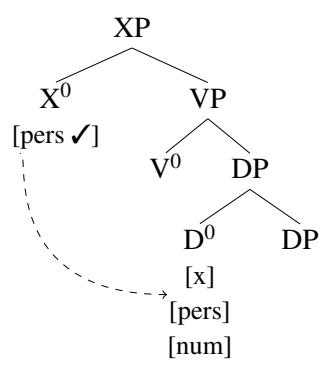

(31) Impoverishment Deletes $[\phi]$

$$
[\phi] \rightarrow \emptyset /[\ldots, \mathrm{x}]
$$


The rule in (31) deletes phi-features on the clitic so that it can no longer be an antecedent for the argument: head ellipsis of that argument will therefore not be possible.

A second kind of deletion involves feature movement. Akin to Chomsky (1995) and Anagnostopolou (1999)'s work on clitic doubling, this second deletion alternative would involve movement of the formal features of the clitic to the $\mathrm{X}^{0}$ head. Specifically, a clitic's phi- and (and potentially D-) features migrate to $\mathrm{X}^{0}$ and will be deleted via an independently motivated Obliteration rule that applies to $X^{0}$ (Bonet 1991, Arregi \& Nevins 2012). ${ }^{10}$

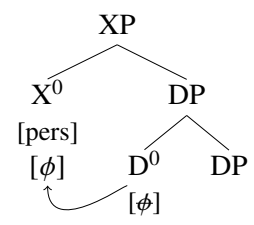

\section{Obliteration Rule} $\left[\mathrm{X}^{0}\right] \rightarrow \emptyset$

In (32), the clitic's phi-features move to $\mathrm{X}^{0}$, and, as in other types of movement, the lower occurrence of the phi-features are deleted. In addition, the Obliteration rule in (33) deletes the $\mathrm{X}^{0}$ node at $\mathrm{PF}$, which accounts for the fact that $\mathrm{X}^{0}$ does not appear to be overtly exponed: i.e., $\mathrm{X}^{0}$ does not surface as object agreement, a clitic, or other morpheme. The moved phi-features of the clitic are consequently deleted along with $\mathrm{X}^{0}$ node. Finally, a third type of deletion is posited: namely, deletion in the syntax via the Agree operation itself.

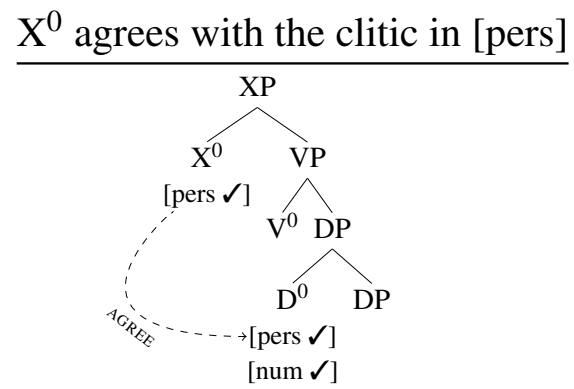

(35)

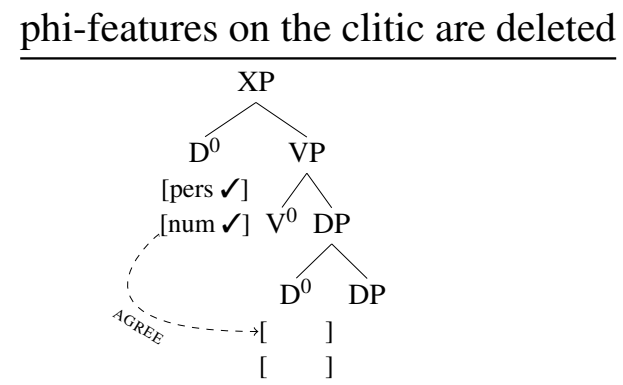

$\mathrm{X}^{0}$ agrees with the clitic and values its person feature (34). But Agree also triggers deletion of the clitic's phi-features (35). Deletion triggered by Agree is tentatively termed "Un-Agree," since, in this context, Agree not only only copies features, but also deletes them. Whether $\mathrm{X}^{0}$ 's person feature should be deleted as well is unknown at present, and I do not pursue the matter further. Nevertheless, one indication that deletion happens in the syntax, not later at PF, is that deletion via Agree explains why clitics cannot interact with $v^{0}$ after they have agreed with $\mathrm{X}^{0}$. Specifically, clitics cannot agree with $v^{0}$ because, by the time $v^{0}$ probes, clitics no longer have any features and cannot be potential goals.

Deletion via $\mathrm{X}^{0}$ is a novel claim, but I submit that this idea is just an expansion of the already existing range of parameters for probes proposed in the syntax literature. For example, theories of Multiple Agree (Hiraiwa 2001, 2005, Zeijlstra 2004, Nevins 2007, 2011, etc.) and Cyclic Agree (Béjar \& Rezac 2009) offer competing accounts of how probes search for appropriate goals within their domains. Further, Béjar and Rezac (2003, 2009) claim that probes can be specified for certain features. Consider, too, work

10 Cf. Himmelreich (2019), who argues for feature deletion of heads triggered by head movement. 
by Deal (2015) on "satisfaction" and "interaction" conditions for probes. "Un-Agree" thus hypothesizes a new parameter for probes, i.e., that they may delete as well as value or copy features. If probes can be specified for valuation of certain features, deletion may, too, be a specification on individual probes. Nevertheless, I will not pursue the issue of deletion mechanisms further in this paper. I leave for future research the question of which option might be most successful. In sum, obligatory doubling of third person accusative strong pronouns is attributed to the corresponding clitics' inability to agree with $\mathrm{X}^{0}$ due to an absence of person features. Optional doubling is derived via alternations in Agree with either $\mathrm{X}^{0}$ or $v^{0}$. Lastly, covert arguments are generated via head ellipsis. But head ellipsis (pro-drop) is blocked when clitics' phi-features have been deleted. The reason why covert (pro-dropped) arguments must be overtly doubled is that clitics in these configurations have retained phi-features (through agreement with $v^{0}$ ) and are viable antecedents. Having presented derivations of both clitic doubling and un-doubling, the next section offers an account of the person-case constraint and person-case constraint repair.

\section{The Person-Case Constraint and Person-Case Constraint Repair}

Beyond doubling, another person-based phenomenon in the pronominal domain exists in JS: the person-case constraint (PCC) (Perlmutter 1971, Bonet 1991). The PCC is a ban on certain clitic combinations that lead to ineffability effects. Although there are several kinds of PCC effects, JS has the Strong PCC: in ditransitive constructions in which both internal arguments are clitics, the direct object must be third person, never first or second (Bonet 1991). Examples of the Strong PCC in JS are:

(36) * Me le recomendó.

1SG.ACC 3SG.DAT recommended.3SG.PRET

"S/he recommended me to him."

(37) *Te me recomendó.

2SG.ACC 1SG.DAT recommended.3SG.PRET

"S/he recommended you to me."

The consultant judged both (36) and (37) to be ungrammatical. Note that for these examples, JS and modern Spanish look identical. This pair of sentences illustrates that the direct object can never be first or second person, irrespective of the person of the dative. Given this ban on person co-occurrences, JS displays another ditransitve configuration: the PCC repair. It is important to point out that the repair construction is not a syntactic repair, but, rather, an alternate construction. As for the PCC itself, the repair construction looks the same for both JS and Spanish.
Me recomendó
a él.

1SG.ACC recommended.3SG.PRET to him

"He recommended me to him."

Te recomendó a mí.

$2 \mathrm{SG}$.ACC recommended.3SG.PRET to me

"He recommended you to me." 
Observe that the dative is expressed as an un-doubled strong pronoun, and the accusative, as a clitic. This analysis argues that the derivational machinery that produces doubling also generates the PCC repair. The analysis implements a widely utilized account of the PCC itself but submits that the repair is produced via the $\mathrm{X}^{0}$ functional head.

\subsection{Deriving the PCC}

A commonly held view is that the PCC is syntactic (Ormazabal \& Romero 2002, 2007, Anagnostopoulou 2003, Béjar \& Rezac 2003, Adger \& Harbour 2007, Nevins 2007, 2011, Richards 2008, Stegovec 2017, Preminger 2019). ${ }^{11}$ Syntactic analyses of the PCC can be generally classified as "one-probe/two-goals"-style accounts (to borrow verbiage from Stegovec (2017)) (e.g., Ormazabal \& Romero 2002, 2007, Anagnostopoulou 2003, 2005, Béjar \& Rezac 2003, 2009, Stegovec 2017, Preminger 2019). Under the "one-probe/twogoals"-style account, there is one licenser $\left(v^{0}\right)$ but two licensees (the dative and accusative clitics). Further, the dative clitic is higher than the accusative and intervenes between $v^{0}$ and the lower accusative. Apart from intervention effects, the other component of deriving the PCC is the Person-Licensing Condition (PLC) (Béjar \& Rezac 2003, 2009, Preminger 2019):

(40) Person-Licensing Condition

An interpretable first or second person feature must be licensed by entering into an Agree relation with a functional category (Béjar \& Rezac 2009: 53).

If a first or second person accusative clitic cannot enter into an Agree relation with $v^{0}$ and have its person feature licensed, the result will be ineffability. According to Béjar and Rezac, if a third person accusative does not enter in an Agree relation with $v^{0}$, it will assume a default person specification as a result of number licensing. On the other hand, for Anagnostopoulou (2003), third person accusatives have no person features. This analysis follows Anagnostopoulou in assuming a lack of person features for third person accusative clitics that double strong pronouns, which thus do not need licensing. A derivation of the PCC is below. Datives are introduced by an applicative head (Harley 2002, Anagnostopoulou 2003)

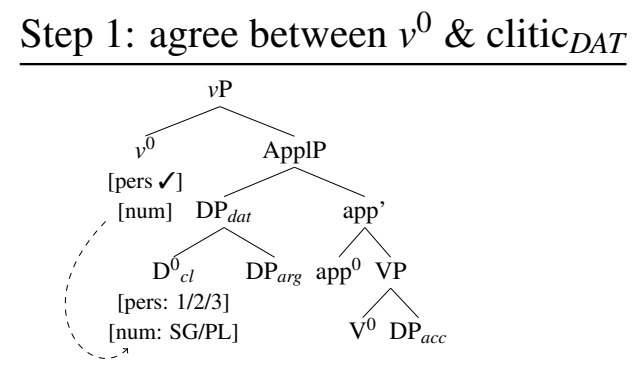

(42) Step 2: agree between $v^{0} \&$ clitic $_{A C C}$

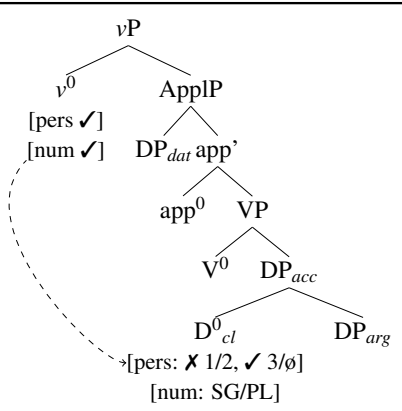

$v^{0}$ is a probe for number and person. As in (41), $v^{0}$ probes the dative clitic first because that clitic is the closest goal that $v^{0}$ c-commands. Dative clitics are always valued for

11 But see Bonet (1991), Miller and Sag (1997), and Boeckx (2000) for morphological approaches. 
person (first, second, or third, doubling strong pronouns and lexical DPs) (cf. Anagnostopoulou 2003). The dative clitic agrees for person with $v^{0}$ but not for number; the number feature on datives is hypothesized to be inaccessible to $v^{0}$ (Taraldsen 1995). $v^{0}$ must therefore probe again to value number. Critically, the person feature on $v^{0}$ is subsequently unavailable for later applications of Agree. The accusative clitic, $\mathrm{D}^{0}{ }_{c l}$ in $\mathrm{DP}_{a c c}$, will bear a person feature if it doubles a first or second person pronoun or a lexical DP. However, the accusative clitic will not have any person feature if it doubles a third person pronoun (absence of a person feature is represented as [Ø] in (42)). $v^{0}$ searches for an appropriate goal on which to value number, which it does on the accusative clitic. If the accusative clitic is first or second person, a crash will result. These syntactically active features cannot be checked by $v^{0}$, since $v^{0}$ 's person feature has already been checked by the dative clitic: the PLC is violated. But if the accusative clitic doubles a third person pronoun, the clitic bears no person feature, and the structure vacuously satisfies the PLC. If the accusative clitic doubles a lexical DP, it will bear an active third person feature (represented here as [3]), but this feature requires no licensing, in accordance with the PLC. The PLC is then vacuously satisfied in this configuration as well, and the structure is well formed.

\subsection{Deriving the PCC Repair}

As exemplified in (38-39), to express combinations of person ineffable in clitic clusters, another construction exists in JS: the PCC repair. In the repair, the dative argument appears as an un-doubled strong pronoun; the accusative remains a clitic. For JS, the term "repair" is somewhat of a misnomer, since un-doubled dative strong pronouns can appear without clitics outside of PCC environments in which clitic clusters are ill formed. JS and Spanish are dissimilar in this regard, as the latter allows un-doubled dative pronouns only in contexts involving ungrammatical clitic combinations. Un-doubled datives are derived via agreement with $\mathrm{X}^{0}$. Specifically, $\mathrm{X}^{0}$ eliminates intervention effects between the higher dative clitic and $v^{0}$, so that $v^{0}$ may agree with the lower accusative clitic.

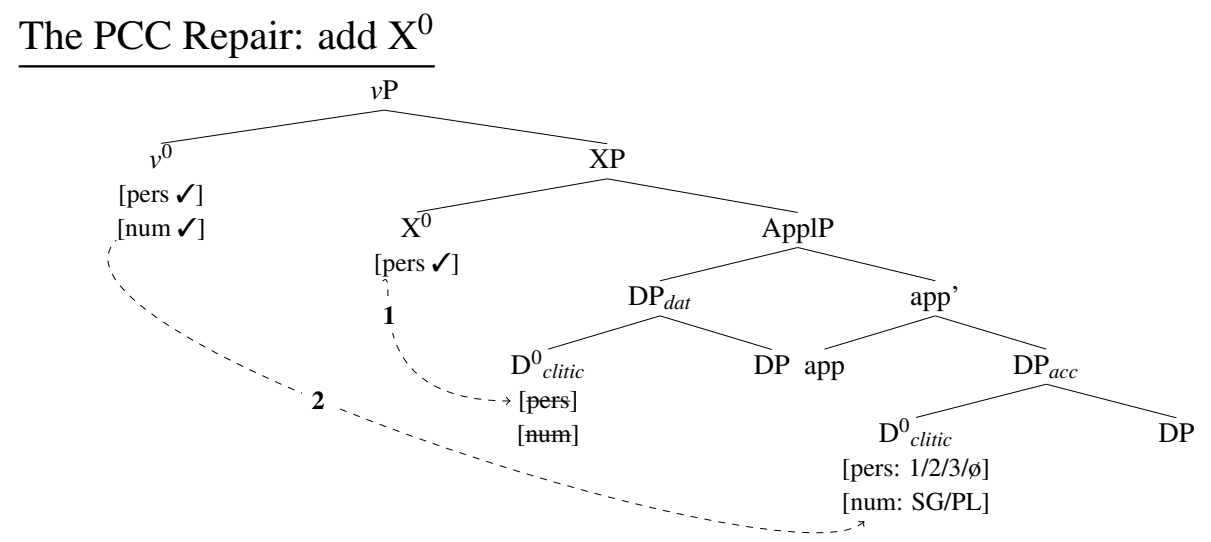

In (43), $\mathrm{X}^{0}$ agrees for person with the dative clitic, which always possesses a person feature. As a result, the clitic is un-pronounced through deletion of its phi-features; the dative argument will be un-doubled. The dative argument must be realized overtly because conditions for head ellipsis are not met (i.e., without phi-features, the clitic cannot be an antecedent). Since the dative clitic has agreed with $\mathrm{X}^{0}$, it cannot agree with $v^{0}$, 
and $v^{0}$ searches for a goal on which to value person and number. The only goal is the accusative clitic, which agrees with $v^{0}$ for both features. Since $v^{0}$ 's person feature has not been checked, person licensing is possible. The accusative clitic may therefore be first, second, or third person. Derivation of the PCC versus the repair is a matter of whether $\mathrm{X}^{0}$ is in the structure, and similarly, derivation of clitic doubling or un-doubling constructions is due to the absence or presence of $\mathrm{X}^{0}$, respectively. As noted in the introduction, Rezac (2011) offers a unifying account of the PCC and PCC repair. For Rezac, the repair (an actual syntactic repair) is derived via insertion of an additional probe on the dative argument. This analysis parallels Rezac's in that both rely on the presence of a second probe to generate the repair. However, this analysis places this additional probe in the clausal spine, whereas in Rezac it is inserted via an interface algorithm.

\section{Conclusion}

This analysis advances several hypotheses concerning doubling and the PCC repair. The first is an optional person probe, $\mathrm{X}^{0}$. The second is that all objects are doubled in the syntax. The third is that the realization of a clitic is regulated by agreement relations with two functional heads. A clitic is un-pronounced, but syntactically generated, if it agrees with $\mathrm{X}^{0}$; it will overtly cliticize if it agrees with $v^{0}$. Obligatory doubling is due to the fact that $\mathrm{X}^{0}$ cannot agree with clitics that lack person features. This paper also sheds light on an endangered and understudied language. JS syntax has not yet been thoroughly investigated, but, as this analysis aims to prove, its syntactic processes may have significant implications for expanding our knowledge of Spanish and Romance languages. Later research on JS might concentrate on dialectical variation, in pronouns or other areas, and on comparisons between JS and Ibero-Romance languages. It is especially imperative to dedicate scientific attention to JS while native and fluent speakers still remain.

\section{References}

Adger, David, and Daniel Harbour. 2007. Syntax and syncretisms of the Person Case Constraint. Syntax 10: 2-37.

Anagnostopoulou, Elena. 1994. Clitic dependencies in Modern Greek. Ph.D. thesis, University of Salzburg.

Anagnostopoulou, Elena. 1999. Conditions on clitic doubling in Greek. In H. van Riemsdijk (ed.), Clitics in the languages of Europe. Language typology, volume III, 762-789. Berlin: Mouton de Gruyter.

Anagnostopoulou, Elena. 2003. The syntax of ditransitives. Evidence from clitics. Berlin: Mouton de Gruyter.

Anagnostopoulou, Elena. 2004. On clitics, feature movement, and double object alternation. In Arthur Stepanov et al. (eds.), Minimality effects in syntax, 15-36. Berlin: Mouton de Gruyter. 
Anagnostopoulou, Elena. 2005. Strong and weak person restrictions, a feature checking analysis. In L. Heggie and F. Ordóñez (eds.), Clitic and affix combinations, 199-235. Amsterdam: John Benjamins.

Anagnostopoulou, Elena. 2017. Clitic doubling. Updated version of the chapter on clitic doubling (2006). In M. Everaert and H. van Riemdsijk (eds.), The Blackwell companion to syntax, 1-56. Oxford: Wiley-Blackwell.

Arregi, Karlos and Andrew Nevins. 2012. Morphotactics: Basque auxiliaries and the structure of spellout. New York: Springer.

Aoun, Joseph. 1981. The formal nature of anaphoric relations. Ph.D. thesis, Massachusetts Institute of Technology.

Aoun, Joseph. 1999. Clitic-doubled arguments. In K. Johnson and I. Roberts (eds.), Beyond principles and parameters, Studies in natural language and linguistic theory, volume 45, 13-42. Springer: Dordrecht.

Baier, Nico. 2016. Unifying anti-agreement and wh-agreement. Ms., University of California, Berkeley.

Baier, Nico. 2018. Anti-agreement. Ph.D. thesis, University of California, Berkeley.

Béjar, Susana, and Milan Rezac. 2003. Person licensing and the derivation of PCC effects. In A.T. Pérez-Leroux and Y. Roberge (eds.), Romance linguistics: theory and acquisition, 49-62. Amsterdam: John Benjamins.

Béjar, Susana, and Milan Rezac. 2009. Cyclic agree. Linguistic Inquiry 40: 35-73.

Belletti, Adriana. 1999. Italian/Romance clitics: Structure and derivation. In H. van Riemsdijk (ed.), Clitics in the Languages of Europe, 543-579. Berlin: Mouton.

Belletti, Adriana. 2005. Extended doubling and the VP-periphery. Probus 17:1-35.

Bleam, Tonia. 1999. Leísta Spanish and the syntax of clitic doubling. Ph.D. thesis, University of Delaware.

Boeckx, Cedric. 2000. Quirky agreement. Studia Linguistica 54: 354-380.

Bonet, Eulàlia. 1991. Morphology after syntax: Pronominal clitics in Romance languages. Ph.D. thesis, Massachusetts Institute of Technology.

Bonet, Eulàlia. 2008. The person-case constraint and repair strategies. In R. D’Alessandro, S. Fischer, and G. Hrafnbjargarson (eds.), Agreement Restrictions, 103-128. Berlin; Mouton de Gruyter.

Borer, Hagit. 1984. Parametric syntax. Dordrecht, Holland: Foris Publications.

Cardinalleti, Anna, and Michael Stark. 1994. The typology of structural deficiency: 
On the three grammatical classes. Ms. University of Venice and University of Geneva/MaxPlanck, Berlin.

Cecchetto, Carlo. 2000. Doubling structures and reconstruction. Probus 12: 93-126.

Cuervo, María Cristina. 2013. Structural asymmetries but same word order. The dative alternation in Spanish. Asymmetry in grammar 1: 117-144.

Deal, Amy Rose. 2015. Interaction and satisfaction in $\phi$-agreement. In T. Bui Bui and D. Özy1ld1z (eds.), NELS 45: Proceedings of the forty-fifth annual meeting of the north east linguistic society, 179-192. Amherst: GLSA, University of Massachusetts.

Déchaine, Rose-Marie, and Martina Wiltschko. Decomposing pronouns. Linguistic Inquiry 33: 409-442.

Drachman, Gaberell. 1983. Parameters and functions of clitic doubling in Modern Greek. Paper presented at the 4th Meeting on Greek Linguistics, University of Thessaloniki.

Dobrovie-Sorin, Carmen. 1990. Clitic doubling, wh-movement, and quantification in Romanian. Linguistic Inquiry 21: 351-398.

Dobrovie-Sorin, Carmen. 1994. The syntax of Romanian. Berlin: Mouton de Gruyter.

Embick, David. 2007. Linearization and local dislocation: Derivational mechanics and interactions. Linguistic Analysis 33:2-35.

Fernández Soriano, Olga (ed). 1993. Los pronombres átonos. Madrid: Taurus.

Fykias, Ioannis. 1988. Aspekte der Neugriechischen Syntax: eine rektions- und bindungstheoretische Untersuchung von Kasus-Mechanismen des Neugriechischen. Ph.D. thesis, University of Salzburg.

Halle, Morris, and Alec Marantz. 1993. Distributed morphology and the pieces of inflection. In K. Hale and S. J. Keyser (eds.), The view from building 20, 111-176. Cambridge, Massachusetts: MIT Press.

Halpern, Aaron. 1998. Clitics. In A. Spencer and A. Zwicky (eds.), The handbook of morphology, 101-122. Oxford: Blackwell.

Harley, Heidi. 2002. Possession and the double object construction. Linguistic Variation Yearbook 2: 31-70.

Himmelreich, Anke. 2019. Feature deletion by head movement - A new solution to agreement asymmetries in Modern Standard Arabic. In A. Murphy (ed.), Structure removal, Linguistische arbeits berichte 94, 385-417. Universität Leipzig.

Hiraiwa, Ken. 2001. Multiple agree and the defective intervention constraint in Japanese. 
In MIT working papers in linguistics, 40: 67-80.

Hiraiwa, Ken. 2005. Dimensions of symmetry in syntax: Agreement and clausal architecture. Ph.D. thesis. Massachusetts Institute of Technology

Jaeggli, Osvaldo. 1982. Topics in Romance syntax. Dordrecht, Holland: Foris Publications.

Jaeggli, Osvaldo. 1986. Three issues in the theory of clitics: case, doubled NPs, and extraction. In H. Borer (ed.), The syntax of pronominal clitics, 15-42. New York: Academic Press.

Kalluli, Dalina. 1999. The comparative syntax of Albanian: On the contribution of syntactic types to propositional interpretation. Ph.D. thesis, University of Durham.

Massey, Victoria Walker. 1992 Compositionality and constituency in Albanian. Ph.D. thesis. University of North Carolina, Chapel Hill.

Miller, Philip H., and Ivan Sag. 1997. French clitic movement without clitics or movement. Natural Language and Linguistic Theory 15: 573-639.

Nevins, Andrew. 2011. Multiple agree with clitics: person complementarity vs. omnivorous number. Natural Language and Linguistic Theory 29: 939-971.

Nevins, Andrew. 2007. The representation of third person and its consequences for Person-Case effects. Natural Language and Linguistic Theory 25: 273-313.

Noyer, Rolf. 1992. Features, positions and affixes in autonomous morphological structure. Ph.D. thesis, Massachusetts Institute of Technology.

Noyer, Rolf. 1997. Features, positions and affixes in autonomous morphological structure. New York: Garland Publishing.

Ordóñez, Francisco. 2012. Clitics in Spanish. In J. Hualde, A. Olarrea, and E. O'Rourke (eds.), Handbook of hispanic linguistics, 423-453. Cambridge: Blackwell.

Ormazabal, Javier, and Juan Romero. 1998. On the syntactic nature of the me-lui and the person-case constraint. Anuario del Seminario Julio de Urquijo, 32: 415-434.

Ormazabal, Javier, and Juan Romero. 2002. Agreement restrictions. Ms., University of the Basque Country (EHU)/Basque Center for Language Research (LEHIA) and University of Alcalá/U. Autónoma de Madrid.

Ormazabal, Javier and Juan Romero. 2007. The object agreement constraint. Natural Language and Linguistic Theory 25: 331-376.

Ormazabal, Javier and Juan Romero. 2013. Object clitics, agreement and dialectical variation. International Journal of Latin and Romance Linguistics, 25(2): 301-344. 
Papangeli, Dimitra. 2000. Clitic doubling in Modern Greek: a Head-Complement relation. UCL Working Papers in Linguistics 12: 473-499.

Philippaki-Warburton, Irene. 1987. The theory of empty categories and the Pro-drop parameter in Modern Greek. Journal of Linguistics 23: 289-318.

Perlmutter, David. M. 1971. Deep and surface structure constraints in syntax. New York: Holt Rinehart \& Winston Inc.

Petkova Schick, Ivanka. 2000. Clitic doubling constructions in Balkan-Slavic languages. In F. Beukema and M. den Dikken (eds.), Clitic phenomena in European languages, 259-292. Amsterdam: John Benjamins.

Preminger, Omer. 2019. What the PCC tells us about "abstract" agreement, head movement, and locality. Glossa: A Journal of General Linguistics 4: 13.

Rezac, Milan. 2008. Phi-Agree and theta-related case. In D. Harbour, D. Adger and S. Béjar (eds.), Phi Theory: Phi-features across interfaces and modules, 83-129. Oxford: Oxford University Press.

Rezac, Milan. 2011. Phi-features and the modular architecture of language. Berlin: Springer.

Richards, Marc. 2008. Defective Agree, case alternations, and the prominence of person. In M. Richards and A. Malchukov (eds.), Scales, 137-161. Universität Leipzig.

Rivas, Alberto M. 1977. A theory of clitics. Ph.D. thesis, Massachusetts Institute of Technology.

Roberts, Ian. 2010. Agreement and head movement. Clitics, incorporation and defective goals. Cambridge, MA: MIT Press.

Saab, Andrés. 2009a. Elipsis nominal y sujetos nulos. Entre la sintaxis y la morfología. Paper presented at SAL 2008, Santa Fe, Argentina.

Saab, Andrés. 2009b. Hacia una teoría de la identidad parcial en la elipsis. Ph.D. thesis, Universidad de Buenos Aires.

Saab, Andrés. 2016. On the notion of partial (non-) pro-drop in Romance. In M. A. Kato and F. Ordóñez (eds.) The morphosyntax of Portuguese and Spanish in Latin America, 49-77. Oxford: Oxford University Press.

Sportiche, Dominique. 1993. Clitic Constructions. Ms., UCLA.

Sportiche, Dominique. 1996. Clitic constructions. In J. Rooryck and L. Zaring (eds.), Phrase structure and the lexicon, 213-277. Dordrecht: Kluwer.

Sportiche, Dominique. 1998. Partitions and atoms of clause structure. Subjects, agreement, case and clitics. London: Routledge. 
Stegovec, Adrian. 2017. Personality disorders: The PCC and two kinds of clitic reordering in Slovenian. In Y. Oseki, M. Esipova, S. Harves (eds.), Proceedings of the 24th formal-approaches to Slavic linguistics conference (FASL), 342-62. Ann Arbor, MI: Michigan Slavic Publications.

Strozer, Judith. 1976. Clitics in Spanish. Ph.D. thesis, University of California, Los Angeles.

Suñer, Margarita. 1988. The role of agreement in clitic-doubled constructions. Natural Language and Linguistic Theory 6: 391-434.

Taraldsen, Tarald Knut. 1995. On agreement and nominative objects in Icelandic. In H. Haider et al. (eds.), Studies in comparative Germanic syntax, 307-327. Dordrecht: Kluwer Academic Publishers.

Torrego, Esther. 1988. A DP analysis of Spanish nominals. Ms., University of Massachusetts, Boston.

Travis, Lisa. 1984. Parameters and effects of word order variation. Ph.D. thesis, Massachusetts Institute of Technology.

Tsakali, Vina. 2006. The syntax and acquisition of pronominal clitics: a crosslinguistic study with special reference to Modern Greek, Ph.D. thesis, University College London.

Uriagereka, Juan. 1988. On government. Ph.D. thesis, University of Connecticut.

Uriagereka, Juan. 1995. Aspects of the syntax of clitic placement in Western Romance. Linguistic Inquiry 26: 79-124.

Uriagereka, Juan. 1996. Determiner clitic placement. In R. Freidin (ed.), Current issues in comparative grammar, 257-295. Kluwer: Dordrecht.

Zeijlstra, Hedde. 2004. Sentential negation and negative concord. Netherlands Graduate School of Linguistics. 